\title{
Valenčič Zuljan, M. and Vogrinc, J. (Eds.) (2011). European dimensions of teacher education - similarities and differences. Ljubljana: The National Education Institute and Faculty of Education, University of Ljubljana. 338 p., ISBN 978-961-253-058-7.
}

Reviewed by Ddr. BARICA MARentič PožARniK, University of Ljubljana

What can be expected when a group of eminent experts in teacher education (TE) is invited to answer a questionnaire and write a report on some facets of recent developments in teacher education (TE) in their respective countries? The result - the collection of reports from 13 European countries - is an interesting publication that can be read in two ways:

- $\quad$ to search for commonalities and differences in a certain area or

- $\quad$ to regard every report as a case study in its own right, to see how

a blend of tradition, given circumstances and context generates particular solutions and also frictions, dilemmas and problems.

Both approaches help us to better understand the interplay of different variables in shaping TE and thus also one's own situation. Solutions presented can be the source of ideas for policy makers and teacher educators. We can not always search for common solutions; the differences among countries can also be seen as enrichment.

The present introduction to the text is not meant to be an »executive summary « of the reports, but a personal selection of interesting common points and also points of diversity in views, problems or solutions.

In the questionnaire, the following three broad areas were covered:

- $\quad$ initial TE (the level education required of teachers, institutions responsible for $\mathrm{TE}$, admission procedures, the renewal of study programmes according to Bologna process, induction period, postgraduate studies,

- in-service training (institutions, areas, financing; teacher promotion policies), and

- $\quad$ broader issues (areas of current discussions, research studies and proposals for further development). 
The texts that resulted from the answers show beside some commonalities a wide variety and diversity of approaches that reflect not only differences between countries but also between experts themselves, their perspectives and conceptions, their personal judgement of what they regarded as important and worth mentioning. One of the important differences is that some case studies are mainly descriptive - presenting data, regulations, describing programmes while others are more problem-oriented, with a personal touch - arguing about solutions, mentioning dilemmas, unsatisfactory processes and open problems, as can be seen already from the subtitles: »Teacher Education in the Netherlands: Balancing between autonomous institutions and a steering government «, »Teacher education in France: persistent tensions between profession and civil service«, »Teacher Education in Norway between scientific ambition and professional relevance."

There are differences already in the introductory section. Some reports start with description of the school system, some give the historical background - and some include theoretical background and main principles that guide curriculum construction and the overall policy of TE. These principles are, for example, mentioned in the report from Estonia, or Finland, among others the serious attempt to bring together high quality academic subject matter knowledge with pedagogical knowledge, metaknowledge and high quality pedagogical skills with reflection as a bridge between academic and professional development.

Another important component of some reports (maybe it should find a place in all of them) is the description of main competencies required from teachers in the changing society as a basis of curriculum renewal. Reports from Sweden, Poland, Norway and some others include a detailed list of knowledge, skills and competences. In Finland and the Netherlands where a broad consensus regarding competencies is being achieved, also the ethical dimension of teacher profession is being stressed. Certainly most of the countries involved have done some efforts in defining competencies, as it is a "conditio sine qua « for any renewal, but not all reports presented them.

\section{The level of education required}

In the descriptions of the renewal of initial TE study programmes according to Bologna process, there are some commonalities. In all countries, teacher education is an area that remains more regulated than other sectors of higher education. It means that TE is at the very centre of public attention. Minimal standards or at least recommendations were set up by ministries or universities. Sometimes, the level of regulation is being regarded as too strict, 
like in the Netherlands where the ministry decides not only about qualification framework, but also about the knowledge base of teachers, even national tests for teachers are being planned.

Following Bologna process, a renewal of TE curricula took place in all countries. They had first to make a decision about the level of the required TE for different types of teachers - whether to educate them at the first or second cycle of studies. The countries like Finland, Estonia, Czech Republic, Croatia, Slovenia, have decided to educate all (except preschool) teachers at the second cycle which means 300 ECTS or the equivalent of 5 years of study (the so-called "masterisation « of TE). Other countries embraced a different, sometimes more flexible system, like Norway, the Netherlands, Sweden (which requires 210 ECTS for preschool and primary teachers and 270 ECTS for subject and secondary teachers). In the Netherlands, all secondary teachers are being educated in a consecutive mode, after finishing the academic study of their subject. In Norway, there are different paths to become a teacher, but usually for a teacher certificate a broad integrated 4-year TE-program at bachelor-level (240 ECTS) is being required. In most of the countries, the minimum of 90 ECTS of subject matter study are required, in Sweden, they require 120 ECTS to teach mother tongue.

For some countries, the transition from the previous situation to Bologna system represented a big challenge and a fundamental structural change. For others, like Finland, that already before had a Master degree for all prospective teachers, Bologna process was more a phase of national analysis and evaluation of the teacher education curriculum than a fundamental change.

\section{Institutions responsible for $\mathrm{TE}$}

are now more or less everywhere part of the universities (the so-called process of »universitisation « of TE which some observe with mixed feelings). The usual, but not universal pattern is that faculties of education are responsible mainly for education of teachers for compulsory school; other faculties (of humanities, art, science ), that offer academic training also for other professions, train secondary school teachers. The fate of specialised institutions, like the French IUMF, is uncertain.

\section{Admission procedures}

As regards admission procedures, we find a great variety among countries. A lot depends on shortage or surplus of teachers for a certain subject or 
area and the number of candidates. Admission procedures have to be better defined when there is more competition for the places, like in Finland or Russia. Usually, there is more interest to study for preschool and primary level than to be a secondary school teacher.

In most of the cases, the main criteria are results of final (usually external) secondary school leaving exams, also combined with school marks and sometimes with exams of knowledge in the subject of academic study (the Netherlands, Poland) or proficiency in English (Sweden). Importance of other characteristics like communication and cooperation skills, interest in education, educational experiences... is being widely recognised, but only rarely included in admission procedures, for example in the form of admission interviews (Croatia, Czech Republic, Romania), more so in the case of primary teachers where also musical abilities play a certain role. Interesting is the case of Estonia where beside academic results also personal characteristics are taken into account, such as interpersonal, communication and cooperation skills. In order to evaluate those, the applicants are given group discussion exercises. At another extreme is Poland where it is against the law for universities to hold additional examinations to test candidate's pedagogical abilities.

In view of these differences, there is certainly still a lot of thinking and research to be done to find the optimal solution and combination of selection and admission procedures. Another problem is how to motivate more able young people to decide and apply for studies in TE.

\section{Curriculum renewal according to Bologna process}

One of the consequences of Bologna process is a more unified and better defined professional part of TE which consists in most cases of 60 ECTS (equivalent of one study year) and includes beside the more traditional components (psychology, didactics, subject teaching methods) increasingly also elements of sociology, philosophy of education, ICT, communication. In some countries, the research methodology, with the stress on action and qualitative research is being included to enable teachers to develop a research orientation to their professional work (Finland, also Slovenia).

This means in many cases also a better balance between academic and professional parts of curricula also for future secondary teachers, where the professional part has been traditionally neglected, sometimes to the point of complete deprofessionalisation - mentioned in case of Czech Republic. The process of "professionalisation « of TE in traditional academic institutions is slow as it requires changes in conception of identity and mission. 
Another common feature of renewed curricula is strengthening of practical school based training, in qualitative and quantitative terms. Many regard this as the central issue of curriculum renewal (see the report from Russia). The practice comprises between 15 and 20 ECTS (which means from 5 up to 15 weeks), but is in many cases still longer and better organised for primary than for secondary teachers. Some countries have already a long-term tradition of an intensive confrontation with the future profession during the studies, from the first year on; others are developing it anew. The practical part has a different focus in different phases, like: initial, observational, subject, research, complex practice in Czech Republic, observation, active teaching under supervision of some lessons and finally independent teaching in Slovenia (better defined for primary than for secondary teachers) or in the Netherlands. In the last case, students have an independent teaching practice for half a year at the end of the study.

The practice is being supervised by university lecturers jointly with mentors from cooperating schools; the partnership of faculties and schools has been strengthened also by the corresponding EU projects, like in Slovenia. In some countries there exist special training schools. In the evaluation of the practice, the portfolio is increasingly being used.

\section{Who are teacher educators?}

In accordance with the process of »universitisation « of TE, teacher educators have to comply to university regulations for appointment and promotion; the criteria are in most cases based entirely on scientific publications, sometimes only in the academic subject field; pedagogical qualifications or practical experiences in teaching (at primary or secondary level) are not required. Also the quality of work with students is rarely taken into account. The Netherlands represents a positive example by defining teacher educators as a separate profession and supporting their professional development. Hopefully, other countries are going to follow this example. On the other hand, the importance of mentors at schools is being increasingly recognised in many countries; more and more attention is given to their status and training.

At the end of the studies, the candidate has usually to write and defend a thesis that is more or less orientated toward the area of teaching. For secondary teachers, it may be based entirely on the academic subject chosen. For primary teachers, the thesis may represent the proof that they can perform research on the problems of their own teaching. 


\section{Induction period, state examination}

Here, there is again a lot of variation among the countries concerned. In some, there is no induction or probationary period at all - the teacher gets the full qualification or licence at the moment of graduation (the Netherlands, Russia). In the case of the Netherlands, maybe the large amount of independent practice in school during studies does make a special induction period less necessary. In Russia, the teacher is fully qualified upon graduation, but gets a mentor to help him/ her at the beginning.

But in most of the cases, the newly qualified teacher spends the first year, maybe two, as a probationer, under a close supervision of a mentor (sometimes also principal) at the school, with part-time teaching duties and a somewhat reduced wage. At the end of this period, there is a state exam which makes him/her a fully licenced teacher. The university institutions are usually not involved in this process, like in Sweden where the induction period is a question for the municipalities or the private schools. The mentor may have less teaching hours as a compensation for the mentoring work. The case of Estonia can be mentioned as an example of a very systematic attempt to give support to newly qualified teachers. In 2004/2005, the induction year programme was initiated for all teachers. They have to attend inservice courses organised by university induction year centres. These centres also train mentors for their task of supporting novice teachers' learning. The evaluation research performed on this induction programme found three areas in need of improvement (this certainly applies also in other countries): to increase novice's readiness for reflection, to train mentors for their role and to increase school principals' readiness to support novice teachers. The training of mentors is being offered in many countries (the Netherlands, Sweden, Slovenia), but is not obligatory.

Also the state exams at the end of probationary period vary a lot in terms of scope and content. In some cases, the process is very demanding, comprising oral and written exams in subject matter, didactics, school laws etc., like a »second diploma« (Romania). In some cases, the candidate has to prove his/her teaching abilities by performing a model lesson before a committee (Croatia). In Slovenia, the candidate has to present documentation of a certain number of observed lessons which were positively evaluated by the mentor and principal and has also to pass exams on the legal system of EU and Slovenia, the legislation in the area of education and in Slovene language.

In most of the countries, postgraduate studies are being offered to teachers, some at the doctoral level, some to qualify to teach another (second or third) subject or to be able to perform special duties (like school counselling, working with children with special needs). 


\section{In-service training and promotion}

In-service training is being organised and offered by universities and numerous other public and also private institutions. The amount of structure and obligations for teachers and schools vary a lot. For example in Romania, every teacher has to collect 90 points from in-service courses every 5 years, half of those from formal in-service; there is a similar situation in Russia that has 100 centres for in-service training of teachers. Also in Poland there is a strong institutional basis, consisting of a national and many local centres. In Slovenia, teachers collect points in accordance with the duration of courses (inservice training seminar that lasts $8-15$ hours is rated with 0.5 points, a seminar that lasts 16-23 hours is rated with 1 point etc.) and those points count toward promotion.

On the contrary, in the Netherlands, there is no national programme or obligation; full responsibility for in-service stays with schools and teachers, there is also a lot of school-based in-service in accordance with school needs. In many countries (France, Croatia, Russia, Slovenia...) the courses in information communication technology and the use of computers in teaching are becoming one of the priorities, set by the governments. Other areas in which teachers express wishes for in-service training are teaching students with special needs, mastering discipline and behaviour problems and class management. Also projects, carried out by school teams, sometimes with international cooperation, represent an excellent way to promote teachers' professional growth and affect deeper changes in thinking and teaching (see examples from France, Slovenia, Finland).

It is interesting to note that the system of teacher promotion with the help of special titles is mentioned only in the reports of former socialist countries, like Poland, Czech Republic, Russia, Croatia, Slovenia, Estonia, Romania. The system is usually quite elaborate. Some examples: in Estonia, there are four consecutive levels - junior teacher, teacher, senior teacher and teacher-methodologist. The first promotion is being performed by the principal, for the next, the teacher has to apply and perform a self-evaluation. In Poland, the titles are trainee teacher (first year), then contract teacher, appointed and chartered teacher. Titles are awarded by special committees, the highest by the Ministry of education.

In Slovenia, the teachers can be awarded the titles of Mentor, Adviser or Consulter, according to detailed regulations. For example: for promotion into the title of mentor, the teacher needs to get at least 4 points from in-service training (points depend on the length of the training) and 3 points from the 
area of professional work (mentoring students, organizing different activities for colleagues, students, parents, doing research, writing articles or textbooks, etc).

All the titles are awarded by the Ministry. In Romania, there are three didactic degrees that are linked to a training programme and formal evaluation. In Russian Federation, there is a national system of grading teachers based on their experience, etnure and level of education. Besides, for very special achievements, teachers can be awarded titles, like Honoured teacher.

The weak point of these systems, mentioned in some of the reports, is an excessive formalisation and bureaucratisation, while the quality of teaching is not being given the proper attention.

In other countries, career promotion does not consist of titles, but of new or expanded professional tasks and responsibilities, linked to the newly acquired competencies, like leading teams or projects, becoming a special needs teacher or counsellor. There are many plans to create master programmes for teachers to expand or create new career opportunities for them.

\section{Open problems and suggestions for improvement}

Let us list here only some of the typical problems and issues, raised in reports:

- a decreasing level of motivation and cognitive abilities of candidates for TE,

- a low social status and self esteem of teachers,

- a shortage of qualified teachers for certain subjects,

- employment of unqualified teachers,

- $\quad$ lack of systematic monitoring and research in TE,

- $\quad$ research results (on teaching, learning...) are not being put to practice,

- teachers are not able and motivated to analyse their performance, participate in team work and learn from each other,

- lack of balance between theory and practice and between academic and professional parts of TE (especially for secondary school teachers),

- occupational burn-out of teachers,

- $\quad$ inability to cope with behavioural problems of students and excessive expectations of parents,

- $\quad$ low level of professional autonomy in face of government control,

- $\quad$ lack of clear policy in this area.

Some suggestions for improvement:

- TE should be based on internationally recognised research,

- a radical change of the philosophy of TE from quantity-oriented to quality-oriented. 
What else is needed?

- formulation of clear professional standards and also criteria to assess them,

- a revision of procedures for accreditation of TE institutions and programmes,

- allocation of sufficient resources,

- $\quad$ improving the flow of information (on didactic recourses, multimedia...) also on international scale,

- $\quad$ increase teacher mobility and different (also international) partnerships.

X X X

\section{The final word}

Let us conclude with an important suggestion from Estonia: there should be focus on coherence and cooperation between actors that enter into this field: state, higher education institutions, responsible for TE and teachers themselves and their associations.

At the moment, diversities seem to be larger than similarities. What about the future? Are national perspectives in TE going to be adapted to and give way to a European perspective? Is it a desirable process? The Swedish report concludes: With knowledge and a comparative perspective our discussions and suggestions probably will be more informed, pragmatic but also critical. There is a similar statement from Romania: »The efforts of harmonisation of teacher training policies and structures in the EU member states should be continued." But not everything can be regulated, as: »Teaching is more than an occupation, it is a mission «. 